\title{
MICROPOLÍTICA DO TRABALHO VIVO EM ATO, ERGOLOGIA E EDUCAÇÃO POPULAR: PROPOSIÇÃO DE UM DISPOSITIVO DE FORMAÇÃO DE TRABALHADORES DA SAÚDE
}

\author{
THE MICROPOLITICS OF LIVING WORK IN THE ACT, ERGOLOGY AND POPULAR EDUCATION: \\ A PROPOSITION OF A DEVICE TO TRAIN HEALTH WORKERS
}

\author{
Suze Rosa Sant' Anna ${ }^{1}$ \\ Élida Azevedo Hennington ${ }^{2}$
}

Resumo O presente artigo tem como objetivos discutir o trabalho em saúde e apresentar um dispositivo para a formação de trabalhadores sob a ótica do conceito ampliado de saúde, fundamentado em três principais referenciais teóricos: a démarche ergológica e seu dispositivo dinâmico a três polos de Yves Schwartz, a cartografia da micropolítica do trabalho vivo em ato de Emerson Elias Merhy e a educação popular em saúde, inspirada em Paulo Freire. Espera-se com este estudo contribuir para a reflexão e a construção de uma estratégia de formação para intensificar a inserção dos estudantes nos cenários de prática que enfatizem a construção compartilhada de conhecimentos e favoreçam especialmente a produção e efetivação de saberes e dos aspectos relacionais que compõem o núcleo tecnológico do cuidado em saúde.

Palavras-chave trabalho em saúde; micropolítica do trabalho vivo; ergologia; educação popular; formação em saúde; ergoformação.
Abstract This article aims to discuss the work done in the health area and to present a tool to train workers under the light of the expanded concept of health, based on three main theoretical frameworks: Yves Schwartz' ergology demarche and its dynamic threepole tool; Emerson Elias Merhy's cartography of the micropolitics of living work in the act; and the popular health education, inspired in Paulo Freire. It is hoped that this study will contribute to a reflection on and to the construction of a training strategy to enhance the integration of students in practical activities that emphasize the shared construction of knowledge and, especially, encourage the production and realization of knowledge and relational aspects that make up the technological core in health care.

Keywords health work; micropolitics of living work; ergology; popular education; training in health; ergotraining. 
O trabalho em saúde, fenômeno sócio-histórico aqui entendido como aquele realizado por diversos sujeitos, profissionais e trabalhadores em geral com formação na área e caracterizado pelo ato de cuidar, com o objetivo de atingir a cura, a reabilitação ou minorar o sofrimento e promover o bem-estar, tem sido tema de importantes discussões por sua complexificação e intensas transformações no mundo contemporâneo. O trabalho humano na saúde como 'atividade enigmática' (Schwartz e Durrive, 2007) tem incorporado novos saberes e novas tecnologias que, mesmo sem alterar significativamente o núcleo tecnológico da produção do cuidado, vêm paulatinamente deflagrando a necessidade de reflexão e de criação de novos dispositivos para o campo da gestão e da formação em saúde (Ferreira, Franco e Merhy, 2009; Hennington, 2008; Merhy et al., 2004; Merhy, 2007; Sant'Anna e Hennington, 2010).

A incorporação de diferentes tecnologias de ponta, equipamentos e instrumentos, a presença de novos modos de organização do trabalho e o desenvolvimento de tecnologias não materiais estimularam a produção de novos produtos ou maneiras diferentes de produzir os antigos (Merhy, 2007; Pires, 1998). A partir desse cenário de intensas transformações, existe também a modificação daquilo que é pedido ou exigido aos homens e às mulheres no trabalho, ou seja, uma adaptabilidade e flexibilidade técnicoinstrumental e intelectual, designada pelo genérico termo 'competências' (Schwartz e Durrive, 2007).

Autores como Mello, Moyses e Moyses (2010) ampliam o rol de mudanças ocorridas no trabalho em saúde, mais precisamente na assistência, ao incluir a necessidade de um heterogêneo universo de 'policompetências' e da integração dos profissionais na assistência, resgatando o sentido do trabalho em equipe multiprofissional, já que este tipo de atividade deixou de se restringir a uma única área de conhecimento e grupos, necessitando cada vez mais da interação de trabalhadores de várias carreiras e níveis de escolaridade partilhando espaços de iniciativa e corresponsabilização (Gomes et al., 2010; Malta e Merhy, 2003).

Novas perspectivas do trabalho em saúde revelam que sua reorganização deve também passar pela implementação de processos educacionais e formativos da força de trabalho, resultando na boa qualidade do produto final ofertado, que deve ser pautada pela prestação de assistência capaz de dar acolhimento e/ou resolução às necessidades sentidas pelos usuários. Outro ponto importante destacado pelos autores é a introdução ou ampliação de dispositivos democráticos de discussão e de decisão, visando a ampliar os espaços de escuta, de trocas e decisões coletivas na gestão dos processos de trabalho.

$\mathrm{Na}$ ótica do conceito ampliado de saúde 3 em contraposição ao marco biomédico, a estratégia de promoção da saúde no Sistema Único de Saúde (SUS) é retomada com enfoque na produção de autonomia da população para o enfrentamento de situações de vulnerabilidade no processo do cuidado 
à saúde, além de procurar estimular que os trabalhadores/formadores reflitam sobre as diferenças culturais e atuem na perspectiva de uma educação humanizadora, crítica, reflexiva e voltada para a formação do homem integral e autônomo (Alves e Aerts, 2011).

Nessa perspectiva, a educação popular em saúde (EPS), inspirada na proposta pedagógica da educação popular de Paulo Freire, constitui-se em uma estratégia de enfrentamento dos problemas de saúde encontrados, procurando fortalecer a relação com a população e os movimentos sociais e criar vínculos entre as equipes de saúde e o pensar e fazer cotidiano da população. Ou seja, a EPS propõe-se à construção de um sistema de saúde em que trabalhadores da saúde e usuários sejam atuantes, participativos, autônomos e críticos (Alves e Aerts, 2011).

Todo este contexto de mudanças do trabalho em saúde revela a necessidade cada vez maior de um esforço coletivo e cotidiano dos sujeitos implicados na atenção à saúde para a elaboração de propostas educativas e de formação dos trabalhadores da área coerente com o processo de fortalecimento do SUS. Além disso, é necessário que outros fatores como a priorização da atenção primária, a ênfase na promoção da saúde, a reorganização de serviços de saúde em rede, a ampliação de espaços democráticos de discussão e de decisão e a implementação de gestão participativa, também, sejam incorporados na reestruturação do trabalho em saúde.

O trabalho em saúde em sua micropolítica e na perspectiva do cuidado, suas tecnologias e as novas conformações da atividade 4 são temas relevantes para as instituições formadoras de trabalhadores na área. Impõe-se estabelecer diálogo e articular referenciais com capacidade de ajudar na compreensão sobre o que é trabalho, os ingredientes necessários para o "agir em competência" em situações de trabalho e o modo cotidiano de se produzir saúde em nossa sociedade, entendendo-se premente a tarefa de pensar maneiras e criar dispositivos, como diria Schwartz, de melhor intervir sobre o trabalho para transformá-lo (Schwartz e Durrive, 2007).

Com base nesse desafio, o presente artigo apresenta um dispositivo para a formação de trabalhadores no campo da saúde promocional fundamentado em alguns referenciais teóricos, especialmente a démarche ergológica e o dispositivo dinâmico a três polos de Yves Schwartz, a cartografia da micropolítica do trabalho vivo em ato de Emerson Elias Merhy e a educação popular em saúde inspirada em Paulo Freire.

\section{Micropolítica do trabalho vivo em ato e tecnologias de produção do cuidado em saúde}

Com objetivo de refletir sobre o modo cotidiano de se produzir saúde no contexto brasileiro, ou seja, refletir sobre a micropolítica ${ }^{5}$ do trabalho vivo 
em ato, Merhy (2007) elaborou sua tese de livre-docência na Faculdade de Ciências Médicas da Universidade Estadual de Campinas (Unicamp), em 2000, intitulada Reflexões sobre as tecnologias não materiais em saúde e a reestruturação produtiva do setor: uma micropolítica do trabalho vivo, que deflagrou a produção de diversos textos e do livro Saúde: a cartografia do trabalho vivo, em 2002, dando continuidade à proposta de discutir o trabalho em saúde, principalmente no território das tecnologias não materiais.

O trabalho em saúde, cuja ação intencional é marcada pela busca da produção de cuidados - bens e produtos - que satisfaçam necessidades, seja do usuário ou do trabalhador ou do serviço, é centrado no trabalho vivo 6 em ato permanentemente e possuidor de tecnologias de ação que se configuram em processos de intervenção em ato que operam como relações, encontros de subjetividades e que se mantêm além dos saberes tecnológicos estruturados (Merhy, 2007).

Essas tecnologias de saúde são configuradas a partir do arranjo entre dimensões materiais e não materiais do fazer em saúde e classificadas por Merhy (2007) como: 1) tecnologias leves - dizem respeito aos aspectos inter-relacionais, tipo produção de vínculo, autonomização, acolhimento, gestão do processo de trabalho; 2) leve-duras - apresentam uma parte estruturada, o conhecimento como a clínica médica, a clínica psicanalítica, a epidemiologia, o taylorismo, o fayolismo, e outra leve, relacionada ao modo de agir singular de cada trabalhador composto de saberes estruturados; 3) tecnologias duras - têm em sua estrutura uma característica dada a priori, como no caso de normas e estruturas organizacionais, ou mesmo aparatos tecnológicos do tipo máquinas e equipamentos.

O reordenamento do núcleo tecnológico do cuidado, com primazia do trabalho vivo sobre o trabalho morto,7 e a incorporação das tecnologias leves e leve-duras, e sua relevância sobre as duras, são elementos importantes para efetivação das mudanças dos modelos de assistência que buscam a garantia do acesso e acolhimento dos usuários, responsabilização/vínculo e gestão participativa. Isto porque possibilitam a superação das situações de repetição dos modelos vigentes, dando ao trabalhador ou à equipe total possibilidade de agir no ato produtivo do cuidado em saúde, com produção de novos produtos e ressignificação de seus atos assistenciais (Ferreira, Franco e Merhy, 2009; Merhy, 2007).

A efetivação da tecnologia leve do trabalho vivo em ato na saúde se expressa como 'relações interseçoras' que estão presentes na produção do trabalho - descrito como ato de cuidar - e consumo (do cuidado) que ocorrem ao mesmo tempo. Quando o trabalhador da saúde se encontra com um usuário no processo de trabalho, segundo Merhy (2007, p. 57), “estabelecese entre eles um espaço interseçor que sempre existirá nos seus encontros, mas só nos seus encontros e em ato", conhecido como uma interseção par- 
tilhada. Neste espaço, segundo o autor, o agente produtor, ou seja, o trabalhador da saúde utiliza-se de suas ferramentas (conhecimentos, equipamentos, tecnologias de modo geral) na busca da realização de um produto/utilidade necessário pelo consumidor (usuário da saúde) ou população, sem, contudo, reduzi-lo a um mero objeto de sua ação, uma vez que permite que expresse suas intencionalidades, conhecimentos e representações sobre o seu processo saúde-doença.

Na perspectiva de formação de redes e de encontros no trabalho em saúde como 'trabalho vivo em ato', o trabalhador, através de uma clínica cuidadora sustentada nas 'relações interseçoras' com o usuário ou coletividade, deve ser produtor de acolhimento, vínculo e responsabilização e também atuar como gerente do cuidado, por meio da mobilização de toda uma rede necessária para realização de um projeto terapêutico (Merhy, 2007). No setor saúde brasileiro existem algumas experiências pioneiras capazes de contribuir para a produção da interseção partilhada, dentre elas a abordagem da educação popular em saúde (EPS), inspirada em Paulo Freire. A EPS está pautada na ampliação da inter-relação das diversas profissões, especialidades, serviços, doentes, familiares, vizinhos e organizações sociais locais envolvidos com um problema específico de saúde e vem procurando identificar e instrumentalizar a diversidade de práticas em saúde emergentes, fortalecendo e reorientando essas práticas, saberes e lutas. Procura valorizar principalmente a mobilização das autonomias individuais e coletivas através do diálogo entre o saber popular e o saber científico, investindo na compreensão, explicitação e reconhecimento de saberes e intervenções dos sujeitos usualmente desconsiderados nas práticas oficiais de saúde.

\section{Educação popular em saúde e a proposta metodológica de interseção partilhada para a produção de cuidado}

A EPS tem como princípios político-pedagógicos fomentar atitudes de participação no sentido de sempre mudar realidades, fazendo com que as informações sobre a saúde dos grupos sociais contribuam para elevar suas enunciações, reivindicações e, por fim, projetar caminhos inventivos, prazerosos e inclusivos que proporcionem mudanças na vida cotidiana das pessoas (Pedrosa, 2007).

A proposta do método da educação popular, sistematizado por Paulo Freire, foi incorporado pelo setor saúde nos anos 1970, tendo como ponto de partida as experiências de serviços comunitários de saúde desvinculados do Estado, o que permitiu uma aproximação deste setor com as classes populares, fato que representou uma ruptura com a tradição autoritária e normatizadora da educação em saúde (Vasconcelos, 2007). A incorporação 
da EPS foi proporcionada pelas lutas sociais pela saúde como direito no movimento de Reforma Sanitária, que trouxe para o debate a necessidade de superação das distâncias culturais entre população e profissionais de saúde (David e Acioli, 2010).

Para Vasconcelos (2008), a proposta da educação popular no setor saúde enfatiza a ampliação dos canais de interação cultural e de negociações do setor junto aos movimentos sociais locais, com propostas de reuniões, cursos, produção de cartilhas, jornais, entre outros materiais e mecanismos de informação e comunicação, cujo objetivo é enfrentar os problemas de saúde locais a partir da integração entre saber técnico e saber popular.

A sistematização da educação popular inspirou a configuração de projetos de pesquisa e reivindicou para Paulo Freire o título de 'criador' de um estilo de pesquisa e ação educativa, que posteriormente foi conhecido como pesquisa participante e pesquisa-ação. Aplicadas ao campo da saúde, estas abordagens têm por objetivo discutir problemas de saúde encontrados na realidade local por meio do diálogo, da problematização e da ação comum entre os grupos sociais e os técnicos e intelectuais para a construção compartilhada de conhecimentos e para organização política necessárias à superação dos problemas encontrados (Stotz, David e Wong-Um, 2005; Vasconcelos, 2007, 2008).

A proposta utilizada na educação popular baseia-se no conceito de dialogicidade de Paulo Freire, que entende a essência da educação como prática de liberdade, pois os homens se fazem, não no silêncio, mas nas palavras, no trabalho, na ação-reflexão:

(...) pronunciando o mundo, os homens o transformam, o diálogo se impõe como caminho pelo qual os homens ganham significação enquanto homens.

Por isto, o diálogo é uma exigência existencial. (...) é o encontro em que se solidarizam o refletir e o agir de seus sujeitos endereçados ao mundo a ser transformado e humanizado (...).

(...) A conquista implícita no diálogo é a do mundo pelos sujeitos dialógicos, não a de um pelo outro. Conquista do mundo para a libertação dos homens (Freire, 2005, p. 91).

A teoria da ação dialógica de Paulo Freire possui quatro características importantes: a 'co-laboração', a 'união', a 'organização' e a 'síntese cultural' . Nessa teoria, a 'co-laboração' acontece quando se tem a comunhão entre as lideranças e as massas populares, pois a comunhão provoca a 'co-laboração', já que os sujeitos se encontram para transformar do mundo em colaboração. E é a partir do diálogo, que é sempre comunicação, que se funda a 'co-laboração' (Freire, 2005).

Para se ter a libertação, é necessária a união que deve ser realizada pelo esforço das lideranças em juntar os oprimidos, que, por sua vez, implica a 
organização das massas populares, não no sentido de justapor indivíduos, mas sim de instaurar o aprendizado dialógico, fazendo com que homens e mulheres se descubram e se reconheçam como seres transformadores da realidade (Freire, 2005).

Por fim, a síntese cultural se desvela como uma modalidade de ação com que, “culturalmente, se fará frente à força da própria cultura, enquanto mantenedora das estruturas em que se forma" (Freire, 2005, p. 209). Dessa maneira, a ação cultural se apresenta como instrumento de superação da própria cultura alienada e alienante, o que desvela que toda ação revolucionária encerra também uma revolução cultural. Para que se tenha a síntese cultural, é necessário utilizar como ponto de partida a investigação dos temas geradores ou da temática significativa do povo, em vez de temas prescritos pela liderança revolucionária.

Para Freire, evidenciar o tema gerador é investigar o pensar dos homens e seu atuar sobre a realidade, que é a sua práxis. Por ser um processo de busca, de conhecimento, de criação, a pesquisa temática exige de seus sujeitos a interpenetração dos problemas, a investigação do próprio pensar do povo que não pode ser feita sem o povo, mas com ele, como sujeito de seu pensar.

A partir da reflexão sobre sua própria situacionalidade, os sujeitos, ao serem desafiados, agem sobre ela. Entretanto, só na medida em que a situação deixa de parecer insolúvel e torna-se passível de resolução, é que surge o engajamento do povo, ou seja, "da imersão em que se achavam, emergem, capacitando-se para se inserirem na realidade que se vai desvelando" (Freire, 2005, p. 118).

O processo de formação e a investigação temática, na concepção problematizadora da educação, tornam-se momentos de um mesmo processo: quanto mais o agente educador investiga o pensar do povo, tanto mais eles se educam juntos. E, ao criarem conjuntamente pautas para a ação, sem negar suas diferenças e suas visões, ocorre o enriquecimento de ambos (Freire, 2005).

No setor saúde, a educação popular, cujas ações são baseadas no diálogo, na escuta do outro e na produção de temas geradores a partir da experiência do outro, deu origem a uma estratégia metodológica cara à saúde pública conhecida como "construção compartilhada de conhecimento", desenvolvida na década de 1990 especialmente pelo Núcleo de Educação em Saúde e Cidadania, da Escola Nacional de Saúde Pública Sergio Arouca, da Fundação Oswaldo Cruz. Esta abordagem, que tem por finalidade a conquista, pelos indivíduos e grupos populares, de maior poder de intervenção nas relações sociais que influenciam a qualidade de suas vidas, considerando as experiências cotidianas dos sujeitos envolvidos no processo, vem sendo apropriada pelo campo da EPS como uma proposta de ressignificação política, social e pedagógica que extrapola o setor saúde, com capacidade 
de facilitar a construção de práticas interativas, cooperativas e dialógicas (Carvalho, Acioli e Stotz, 2001).

Desse modo, a educação popular revela pressupostos para a construção de um espaço de interseção partilhada e coletiva do trabalho em saúde, pois é nos encontros em ato que o profissional de saúde produz e se produz com o usuário, permitindo que este participe ativamente, pelo diálogo, da problematização e da proposição das formas de enfrentamento dos problemas de saúde encontrados individualmente e na realidade local, na busca da realização de um produto/utilidade - a saúde.

\section{Reflexões sobre o trabalho como atividade, competências para o trabalho e ergoformação a partir do referencial da démarche ergológica}

Para Brito (2005) a compreensão do trabalhador e seu trabalho vivo poderia ser enriquecida com o patrimônio de descobertas com base na abordagem da ergologia, que compreende que todo trabalho passa incontornavelmente pelo encontro com o real.

A ergologia foi proposta por Yves Schwartz e por uma equipe de pesquisadores em Aix-en-Provence, na França, na década de 1980, como um projeto "de melhor conhecer e, sobretudo, de melhor intervir sobre as situações do trabalho para transformá-las" (Schwartz e Durrive, 2007, p. 25). Seus referenciais teóricos e metodológicos essenciais derivam da ergonomia francesa na herança de Alain Wisner do Conservatoire National des Arts et Métiers (CNAM), de Ivar Oddone 8 e do aporte da filosofia da vida de George Canguilhem (Schwartz, 2006). Esta perspectiva reconhece o trabalho/atividade como debate de normas e valores que nos conduz ao humano, sempre enigmático, porque vivo, em atividade (Schwartz e Durrive, 2007).

A proposta da ergologia é discutir o trabalho e produzir conhecimento sobre ele, considerando: o conhecimento e a experiência dos trabalhadores, o geral e o específico da atividade, suas normas e variabilidades, e a exigência da conversa entre as várias disciplinas, além do constante questionamento a respeito de seus saberes. Para Schwartz (2000), a ergologia não é, portanto, uma disciplina no sentido de um novo domínio do saber; ela se distingue da disciplina epistêmica que, para produzir saber e conceito no campo das ciências experimentais, deve, ao contrário, neutralizar os aspectos históricos. A démarche ergológica, mesmo tendo como objetivo construir conceitos rigorosos, deve indicar nestes conceitos como e onde se situa o espaço das ressingularizações parciais inerentes às atividades de trabalho.

Para Schwartz e Durrive (2007) o trabalho jamais é pura execução, pois, para gerir a atividade, o trabalhador deve fazer "usos de si", ou seja, recorrer às suas próprias capacidades, seus próprios recursos e fazer suas próprias 
escolhas para produzir algo. A ergologia considera o conjunto em interpelação: de um lado, homens e mulheres; de outro, suas histórias, seu meio de vida, e na interseção destes é que se encontra o trabalho. Segundo Brito (2005), o ângulo a partir do qual Schwartz observa o trabalho é aquele que tende a ser negado ou mesmo ignorado pelas organizações: é o ângulo da vida, do trabalho vivo; é encontrar a vida presente no processo de trabalho.

Entendendo que o trabalho em saúde realiza-se, sobretudo, por meio do trabalho vivo em ato, isto é, o trabalho humano no exato momento em que é executado e que determina a produção do cuidado (Merhy e Franco, 2008b), percebe-se que o componente importante nesse processo é o trabalhador e suas competências para produção na saúde. Neste sentido, podemos considerar o trabalho em saúde como enigmático e complexo, pois a produção em saúde não existe por si mesma, mas necessita que o trabalhador assuma o papel de verdadeiro arquiteto, utilizando diversas tecnologias de trabalho instrumentos, normas, máquinas, um conjunto de conhecimentos e agires, que estão dispersos nas experiências e modos singulares de cada profissional de saúde operar seu trabalho vivo em ato para conduzir a produção do cuidado diário (Merhy et al., 2004; Merhy e Franco, 2008a; Mello, Fugulin e Gaidzinski, 2007).

Buscando referenciais que focalizem as competências profissionais, encontramos no trabalho de Schwartz um caminho para a integração da teoria e da prática na formação de profissionais de saúde. O autor é enfático ao afirmar que competência para o trabalho é um exercício necessário e, ao mesmo tempo, uma questão insolúvel. A competência profissional é uma forma de definir uma competência para uma situação de trabalho, entretanto, uma situação de trabalho é algo que não se pode definir nem limitar, logo, fica clara a dificuldade de delimitar o que podem ser competências da atividade em uma situação de trabalho. Entretanto, Schwartz considera que "é legítimo examinar a questão da competência, porque nenhuma atividade humana pode deixar de lado a possibilidade de pessoas engajadas numa operação responderem positivamente e operarem com eficácia tendo em vista o objetivo comum" (Schwartz e Durrive, 2007, p. 208).

Nesse sentido, o que Schwartz (1998) propugna é que a competência para o trabalho é uma combinatória problemática de ingredientes heterogêneos que devem ser analisados na perspectiva ergológica, já que as competências são antes de tudo um 'agir' aqui e agora, ou seja, é impossível separar competências das 'dramáticas do uso de si', pois cada um soluciona os problemas colocados por meio do trabalho a partir de seu patrimônio, através da mediação do 'corpo-si': da linguagem, dos valores, dos momentos da vida biológica, psíquica, política e cultural.

Para o autor, é através desse corpo-si, entidade mais enigmática que a definição de sujeito e subjetividade, que o trabalhador deixa de ser objetivado 
pelo trabalho e realiza sua atividade através do 'uso de si'. Segundo Schwartz, o corpo-si do trabalhador não é inteiramente biológico nem inteiramente cultural ou consciente. Ele é, na verdade, o resultado de toda a sua história, de sua experiência de vida, suas paixões, seus desejos e patrimônio (Schwartz e Durrive, 2007; Barros, 2007).

De acordo com Schwartz e Durrive (2007), para mobilizar o corpo-si numa situação de trabalho, é necessário mobilizar competências tendo em vista um objetivo comum. A operacionalização das competências da atividade em uma situação de trabalho é difícil, considerando que as situações de trabalho são imprecisas, jamais descritíveis e padronizáveis.

Para os autores, existem três elementos presentes na noção de competência, são elas: a apropriação de um certo número de normas antecedentes, ou seja conceitos que foram transmitidos e codificados para situações e trabalho; a presença de algo inteiramente diferente e inédito em relação às normas antecedentes da situação de trabalho e, por fim, a exposição ao inédito, quando as pessoas devem se remeter a si próprias para gerir algo novo, articulando uma série de experiências heterogêneas, fazendo escolhas para “agir em competência" (Schwartz e Durrive, 2007).

Entretanto, para agir em competência na perspectiva ergológica tornase importante suscitar o "dispositivo dinâmico a três polos" (DD3P), que, segundo Schwartz e Durrive (2007),

(...) é um lugar do encontro, o lugar do trabalho em comum em que se ativa uma espécie de espiral permanente de retrabalho dos saberes, que produz retrabalho junto às disciplinas, umas em relação às outras, portanto, que transforma eventualmente um certo número de hipóteses, de conceitos entre as disciplinas (Schwartz e Durrive, 2007, p. 269).

De acordo com Neves (2008), o DD3P é composto pelo polo dos conceitos, pelo polo da experiência e por um terceiro, ético e epistêmico, que efetua a ligação entre os dois primeiros. Esse dispositivo é uma consequência direta da ideia de renormatização da atividade. O primeiro polo - do conhecimento sistematizado - encontra-se com o segundo - dos saberes gerados nas atividades - em uma contínua dinâmica de renormatização. Esse encontro é realizado na presença de um terceiro polo - das exigências éticas e epistemológicas - que pressupõe uma maneira de olhar o outro como semelhante.

O terceiro polo corresponde ao do questionamento: é descrito como eixo socrático em duplo sentido, em que a reunião dos diferentes protagonistas em torno do que se passa no trabalho supõe uma espécie de requisito que é, ao mesmo tempo, uma exigência de aprendizagem, de domínio de conceitos e verbalização do trabalho e, também, de "imprendizagem" 
(Schwartz e Durrive, 2007), descrita como a humildade em face da atividade de trabalho que representa uma mina de informações acerca da forma como se podem colocar em uso os saberes constituídos no segundo polo. A utilização deste esquema retrata que, no 'encontro do trabalho', nunca se sairá incólume, pois a dinâmica a três polos engaja todos os seus protagonistas.

O DD3P tem uma grande diversidade de aplicação, a exemplo de Trinquet (1996), que desenvolveu o dispositivo em uma empresa com objetivo de controlar os riscos do trabalho; de Durrive (2004), que o utilizou no campo da formação, e Figaro (2008), que adaptou o dispositivo no campo da comunicação.

A 'ergoformação' ou formação ergológica é outro modo de se utilizar o DD3P no ofício de formador, cuja finalidade é conduzir uma atitude de humildade investigativa que restitui a cada um sua parcela de existência, de participação no mundo, em sua história e na produção de saberes. A utilização do DD3P no campo da formação tem por objetivo:

(...) ajudar uma pessoa a colocar em palavras aquilo que ela vive em situação de produção, porque o ponto de vista de cada um sobre seu próprio trabalho não está nunca totalmente pronto para ser comunicado. É um longo e paciente exercício de construção. Um verdadeiro esforço, mas que é muito útil porque ele abre muitas portas, facilita a resolução de problemas num sentido amplo: o desenvolvimento de competências (Schwartz e Durrive, 2007, p. 298, grifo dos autores).

A ergoformação não pretende anunciar uma nova pedagogia, mas é um meio "de apreender, um pouco que seja, a vivência no trabalho que escapa ao que está no registro do emprego ou ofício; de colocar a partir daí férteis questões, o que é fundamental para progredir em um percurso de inserção profissional" (Schwartz e Durrive, 2007, p. 298).

Segundo Schwartz e Durrive, a ergoformação visa a permitir a uma pessoa adquirir meios de gerir uma situação que muda sem cessar, ou seja, saber-fazer. Portanto, para isso ela precisa ter uma dupla leitura de cada situação de trabalho: as instruções e as oportunidades.

No registro das instruções (que podem ser dispostas através de palavras, categorias, podendo então ser escritas, transmitidas e medidas), da antecipação, a pessoa encontra-se no domínio do codificado. No registro das oportunidades, vivido nos encontros com a situação de trabalho, a pessoa encontra-se na atividade. É a pessoa engajada no seu trabalho. E esta situação somente poderá ser analisada depois da vivência da situação. Somente quando a pessoa envolvida no trabalho conhece bem as instruções e ao mesmo tempo está atenta às oportunidades, de modo a relacionar as duplas leituras, ela pode ser considerada competente.

Portanto, para desenvolver competência é necessário que o sujeito conheça as instruções e simultaneamente fique atento às oportunidades in loco, ou 
seja, no campo de atuação, de modo que seja possível alterar a norma. A competência de um trabalhador não se resume a aplicar os procedimentos, está sim em realizá-los em um ambiente material e humano submetido a mudanças permanentes (Schwartz e Durrive, 2007).

Com base no repertório teórico sobre trabalho em saúde e na construção de competências com base na ergoformação, percebe-se que mudanças nas práticas de formação em saúde são necessárias e urgentes. É preciso investir em estratégias que impulsionem a comunicação e interação dos sujeitos e seus saberes como eixo principal da atenção nas práticas de saúde, estimulando a lateralidade e a circularidade desses saberes nos processos de ensino-aprendizagem para uma transversalização de ações e de sujeitos no ato de cuidar.

Reconhecendo que todas essas mudanças e reflexões teóricas interferem diretamente no campo da formação de trabalhadores, pretende-se a seguir descrever uma estratégia intitulada "Comunidade ampliada de pesquisa em promoção da saúde", dispositivo de formação cujo objetivo é intensificar a inserção dos trabalhadores de saúde nos cenários de práticas da saúde promocional que resultem em (trans)formações no trabalho em saúde.

\section{A estratégia "Comunidade ampliada de pesquisa em promoção da saúde"}

Com objetivo de criar um ambiente propício ao desenvolvimento de competências profissionais para o campo da saúde e trabalho em saúde, propõe-se o dispositivo de formação denominado "Comunidade ampliada de pesquisa em promoção e educação em saúde" (CAP-PES), que teve como um primeiro esforço para sua construção teórica o artigo publicado por Sant'Anna e Hennington (2010).

A CAP-PES foi inspirada na ergologia e na educação popular e concebida como um espaço de reflexão/ação análogo à "comunidade científica ampliada" de Oddone, com o diferencial de incorporar uma nova perspectiva com a aplicação do DD3P. O eixo inicial da CAP-PES é a compreensão do processo saúde-doença a partir de uma pesquisa sobre as condições de saúde de uma comunidade, na perspectiva de (trans)formação e (re)construção de conhecimentos para o trabalho em saúde, baseados nos conceitos da promoção da saúde e em referenciais que visam ao diálogo numa interseção compartilhada do conhecimentos.

A CAP-PES pretende ser uma proposta de pesquisa-formação que poderá ser realizada no campo da formação em saúde, tendo por eixo metodológico o DD3P representado pelo esquema de Schwartz e adaptado por Durrive (Schwartz e Durrive, 2007; Figaro, 2008), com o objetivo de 
dotar o trabalhador, ou futuro trabalhador, de ferramentas/meios de gerir uma situação que muda sem cessar, ou seja, saber-fazer o trabalho vivo em saúde.

Os polos do dispositivo da CAP-PES estão assim representados: no polo A, temos os conhecimentos constituídos no campo da saúde, em especial da saúde coletiva e de outras disciplinas que se articulam com o campo - são os saberes científicos, referentes ao aporte conceitual de promoção da saúde e redução das vulnerabilidades, vigilância em saúde e da educação em saúde, entre outros. No polo B, temos a atividade, ou seja, o agir produtivo experimentado no cotidiano sobre as formas de realizar o trabalho em saúde. No polo C, temos a formulação de questionamentos originados pelo desconforto intelectual que se colocam como conhecimentos a serem construídos na relação entre os diferentes polos. É a dinâmica entre o conhecimento científico e a experiência, tendo como princípio as mútuas convocações, combinando desconforto intelectual e humildade epistemológica, através de encontros e diálogos que possibilitem os diversos sujeitos a enfrentar as infidelidades do meio (Canguilhem, 1982), levando-os a desenvolver competências na área da promoção da saúde. Para ativar o polo C, utilizaremos os princípios da ergoformação, que consistem em ajudar uma pessoa a colocar em palavras aquilo que ela vive em situação de produção, a partir de uma dupla leitura de cada situação de trabalho: as instruções e as oportunidades (Schwartz e Durrive, 2007).

A perspectiva metodológico-pedagógica que buscamos ampliar com a CAP-PES visa à articulação crítico-criativa em torno de um espaço coletivo capaz de fazer imergir o profissional da saúde na experiência de vida/saúde a partir do confronto entre a experiência direta e a reflexão conceitual, possibilitando a apreensão da produção de saberes investidos para transformar o trabalho em saúde. A proposta metodológica a ser utilizada tem também como fundamentação a educação popular e suas ações baseadas no diálogo, na escuta do outro e na construção compartilhada de conhecimento.

Para delinear os aspectos estruturais/operacionais da CAP-PES, buscou-se no referencial de Bezerra, Cazarin e Alves (2010) elementos que permitissem, a partir da elaboração e elucidação de alguns questionamentos, diagramar o funcionamento de uma estratégia e os componentes necessários para sua operacionalização, conforme pode ser observado na construção do dispositivo teórico/lógico (DMTL) da CAP-PES (ver Quadro 1, na p. 237).

Com a finalidade de expor o processo de formulação e elaboração da CAP-PES, serão detalhadas a seguir as informações essenciais que subsidiaram a diagramação do funcionamento da proposta. 


\section{Os passos para modelagem da estratégia CAP-PES}

Conforme descrevem Bezerra, Cazarin e Alves (2010), para delinear um programa/proposta de intervenção em saúde, é importante responder a alguns questionamentos que explicitam seus aspectos essenciais. O primeiro questionamento para a construção do dispositivo em foco diz respeito à identificação do problema que gerou a necessidade de criação da CAP-PES voltada para formação de trabalhadores de saúde.

A reorganização produtiva do trabalho em saúde, em decorrência das mudanças ocorridas no mundo do trabalho, impôs à esfera da formação a urgência de criação de dispositivos capazes de provocar mudanças na formação de profissionais de saúde que sejam coerentes com a construção do SUS, que priorizem a atenção primária com ênfase na promoção da saúde, na organização de serviços na perspectiva de rede e no fomento da gestão participativa.

O objetivo geral do dispositivo de formação CAP-PES é criar um ambiente capaz de fazer o trabalhador de saúde imergir na experiência de vida/saúde no campo da saúde promocional e possibilitar o desenvolvimento de competências profissionais, produção de novos saberes e (trans)formação do trabalho em saúde, utilizando ferramentas teórico-conceituais e metodológicas da cartografia do trabalho vivo em ato, da educação popular e da ergologia.

Seus objetivos específicos são: 1) proporcionar espaço para a apresentação e discussão das inovações e produção de conhecimentos técnico-científicos e vivências em ações e práticas de saúde, por meio de oficinas de promoção e educação em saúde que capacitem o trabalhador para realização de um estudo de campo; 2) desenvolver uma pesquisa de campo que possibilite inserir o trabalhador da saúde na discussão do processo saúde-doença presente no cotidiano de vida de uma comunidade; 3) formar grupos de discussão/ação com trabalhadores da saúde e sujeitos do estudo de campo, a fim de proporcionar experiência das dramáticas do aprender a pensar, do aprender a enfrentar os problemas encontrados na realidade local e de construir suas práticas de saúde e projetos de intervenção de forma emancipatória, por meio do diálogo e da construção compartilhada do conhecimento; 4) investigar através de entrevistas/grupos focais o encontro do trabalho, na perspectiva da ergoformação, que busca conhecer os saberes produzidos a partir das experiências vividas pelos trabalhadores participantes da CAP-PES.

O público-alvo seriam os trabalhadores da saúde ou trabalhadores em formação da área da saúde, independentemente da categoria profissional.

Antes de iniciar a intervenção será necessário organizar os aspectos estruturais/organizacionais do dispositivo de formação, como a elaboração de oficinas de atualização teórica e realização de visitas técnicas em espaços produtores de ações de promoção da saúde; capacitação teórica e prática para realização da pesquisa de campo e agendamentos de espaços físicos para aulas, 
palestras, grupos de discussão e a própria pesquisa de campo. É de suma importância a elaboração de um projeto de pesquisa específico para o estudo de campo, e que o mesmo seja submetido e aprovado por um comitê de ética e pesquisa.

Para compreender melhor a proposta de capacitação de profissionais de saúde através do dispositivo de formação CAP-PES, torna-se necessário elencar os componentes/etapas essenciais e suas respectivas atividades que serão detalhadas simultaneamente. Para fins didáticos, a CAP-PES foi organizada em quatro etapas que estão em conformidade com os objetivos específicos propostos pelo dispositivo.

- Primeira etapa: Organização da capacitação dos profissionais de saúde na oficina de atualização em promoção e educação em saúde

Com o intuito de recrutar os trabalhadores, propõe-se como etapa inicial uma oficina de atualização cuja finalidade é captar e capacitar trabalhadores da saúde, ou futuros trabalhadores, com os seguintes objetivos: apresentar e discutir temas atuais do campo, como conceito ampliado de saúde e promoção da saúde; proporcionar vivências através de visitas técnicas em espaços produtores de ações de promoção da saúde e na perspectiva da construção compartilhada de saber; e habilitar o trabalhador para participar de um estudo de campo.

Para inscrição na oficina, os trabalhadores deverão ser informados dos objetivos do estudo e aceitar participar do dispositivo. Após o recrutamento e a capacitação dos profissionais, eles serão convidados a participar da segunda etapa do projeto de intervenção/formação.

Quadro 1 - Dispositivo teórico-lógico da estratégia CAP-PES

\begin{tabular}{|c|c|c|c|c|c|}
\hline Etapas da CAP-PES & Estratégias e recursos & Atividades & Produtos & $\begin{array}{l}\text { Resultados } \\
\text { intermediários }\end{array}$ & Resultado final \\
\hline $\begin{array}{l}\text { - Oficina de atualização } \\
\text { em promoção e } \\
\text { educação em saúde } \\
\text { - Estudo de campo } \\
\text { - Grupos de discussão } \\
\text { (Diálogo e construção } \\
\text { compartilhada do } \\
\text { conhecimento) } \\
\text { - Investigação do } \\
\text { encontro do trabalho }\end{array}$ & $\begin{array}{l}\text { - Aulas expositivas } \\
\text { - Palestras e dinâmicas } \\
\text { - Capacitação técnica } \\
\text { - Visitas técnicas } \\
\text { - Pesquisa em saúde } \\
\text { - Grupos de discussão } \\
\text { - Sala de aula } \\
\text { - Recursos audiovisuais } \\
\text { - Materiais de informática }\end{array}$ & $\begin{array}{l}\text { - Realização de estudo } \\
\text { de campo sobre as condições } \\
\text { de vida de uma comunidade } \\
\text { - Realização de grupos de discussão da } \\
\text { CAP-PES - a construção compartilhada } \\
\text { do conhecimento sobre promoção e } \\
\text { educação em saúde } \\
\text { - Realização da investigação sobre o } \\
\text { encontro do trabalho, ativando o } \\
\text { terceiro polo do DD3P com base na } \\
\text { ergoformação }\end{array}$ & $\begin{array}{l}\text { - } 100 \% \text { dos } \\
\text { trabalhadores } \\
\text { capacitados } \\
\text { para atuar } \\
\text { no campo } \\
\text { da promoção } \\
\text { e educação } \\
\text { em saúde }\end{array}$ & $\begin{array}{l}\text { - Produção de } \\
\text { saberes, } \\
\text { tecnologias de } \\
\text { cuidado e } \\
\text { práticas baseada } \\
\text { nos conceitos } \\
\text { da promoção da } \\
\text { saúde, no diálogo } \\
\text { e na construção } \\
\text { compartilhada do } \\
\text { conhecimento } \\
\text { em saúde com a } \\
\text { comunidade }\end{array}$ & $\begin{array}{l}\text { - Formação de } \\
\text { trabalhadores } \\
\text { de saúde } \\
\text { competentes } \\
\text { para atuar } \\
\text { no campo } \\
\text { da saúde } \\
\text { promocional } \\
\text { e capazes } \\
\text { de transformar } \\
\text { as práticas } \\
\text { de saúde }\end{array}$ \\
\hline
\end{tabular}

Fonte: Adaptado de Bezerra, Cazarin e Alves (2010). 
- Segunda etapa: Proposição de um estudo de campo

Com a finalidade de criar um ambiente capaz de fazer o trabalhador imergir na experiência de vida/saúde, propõe-se um estudo de campo cuja finalidade é disparar o movimento de reflexão e análise da situação de saúde de uma população e "conhecer melhor o chão em que pisamos" (Brandão, 2006, p. 133).

Assim, torna-se interessante que o estudo se realize em uma comunidade próxima ou conhecida, por exemplo, escola, comunidade, igreja ou centro de saúde. É importante que seja sugerido algum tipo de pesquisa já validado em literatura, a exemplo dos inquéritos de saúde. ${ }^{9}$ Antes de aplicar o inquérito, a população alvo deverá ser esclarecida sobre os objetivos da pesquisa e autorizar sua participação, conforme os preceitos da resolução n. 196/1996.

Os dados da pesquisa deverão ser analisados e discutidos e, posteriormente, divulgados e re(produzidos) em palestras, grupos de estudos e/ou grupos focais. Após divulgação da situação de saúde, é recomendável realizar um debate com a população alvo do inquérito, num processo de 'coanálise' e de discussão das formas de enfretamento dos problemas referentes ao processo saúde-doença identificados, bem como fazer aflorar outros temas geradores, ou seja, as temáticas significativas de saúde que afligem a comunidade em questão.

Ao final dos debates, é importante convidar a comunidade onde foi realizado o inquérito para participar também dos grupos de discussão da CAP-PES que serão realizados na terceira etapa deste estudo.

- Terceira etapa: Organização dos grupos de discussão da CAP-PES - o 'espaço interseçor' para construção compartilhada do conhecimento sobre promoção e educação em saúde

Esta etapa consiste em fomentar espaços de diálogo entre profissionais participantes da CAP-PES e a população alvo sobre a situação de saúde constatada na pesquisa de campo, com objetivo de promover a organização política necessária à superação dos problemas encontrados a partir da construção de propostas de promoção e educação em saúde.

Proposto por Paulo Freire, o referencial metodológico a ser utilizado para subsidiar este 'espaço interseçor' dos grupos de discussão serão os círculos de estudo, cujo objetivo é atribuir um papel ativo aos profissionais de saúde e à população alvo (usuários) na produção de conhecimento coletivo, considerando como imagem-objetivo a transformação da realidade social e a possibilidade de melhora do nível de vida das pessoas imersas nessa realidade (Brandão, 2006).

Nesses grupos de discussão será desenvolvida a análise crítica dos problemas identificados, num diálogo-debate sobre as formas de enfrentamento por meio de um movimento de transversalidade comunicacional e do compar- 
tilhar conhecimentos na busca de ações e práticas com capacidade de intervir na realidade, visando à construção de vidas mais saudáveis.

Após a finalização do grupo de discussão, os profissionais de saúde, valendo-se da análise dos dados do inquérito e do processo - de tudo o que acon-teceu durante todo o transcorrer do trabalho -, deverão propor atividades de promoção e educação em saúde a partir do conhecimento compartilhado de saúde desenvolvido na CAP-PES.

- Quarta etapa - Investigação do encontro do trabalho - ativando o polo C do DD3P com base na ergoformação

Nesta etapa será realizada uma investigação que busca conhecer os saberes produzidos a partir das experiências vividas pelos trabalhadores participantes da CAP-PES, ou seja, conhecer "o ponto de vista daquele que trabalha" (Schwartz e Durrive, 2007, p. 297) da perspectiva da ergoformação, que entende que, quando o sujeito se retira do trabalho para refletir e tirar os ensinamentos do vivido e retorna em seguida, este processo torna o trabalho formador (Schwartz e Durrive, 2007).

Para produção de dados, propõe-se a realização de entrevista semiestruturada. Os dados serão registrados através de gravador e diário de campo da equipe de docentes integrantes do projeto e depois transcritos.

A entrevista deverá ter como questões norteadoras: "conte-me como foi, para você, participar do CAP-PES", que tem por objetivo 'quebrar o gelo', introduzir o tema em foco e construir uma interação com o pesquisado; "conte-me sobre as atividades desenvolvidas por você na CAP-PES", que visa a fazer a leitura das instruções (reconhecimento) das atividades, ou seja, possibilitar que os trabalhadores destaquem e listem os principais procedimentos, atividades, práticas desenvolvidas, as normas antecedentes. É o olhar sobre a generalidade da situação, ou seja, decodificar uma situação pelo "ângulo das informações estáveis, aquelas que são pensadas de antemão, de certa forma informações frias porque duráveis" (Schwartz e Durrive, 2007, p. 304).

Por fim, a última questão norteadora será: “conte-me como foi realizar cada atividade desenvolvida por você na CAP-PES", que tem por objetivo fazer a leitura da atividade pelo ângulo das oportunidades (ancoragem). Esta questão pretende que o trabalhador fale com base na "vivência da situação", ou seja, que ele faça uma "releitura da mesma situação, mas da perspectiva do ser vivo, com engajamento da pessoa referida. As informações recolhidas são 'quentes' no sentido de que são sensíveis, arriscadas, efêmeras, pois mal são recolhidas, já estão superadas” (Schwartz e Durrive, 2007, p. 304).

Os dados serão categorizados com base na dupla leitura da atividade: as instruções (reconhecimento) e as oportunidades (ancoragem), conforme descrito por Schwartz e Durrive. Com base nessa dupla leitura, serão construídas as categorias analíticas das competências desenvolvidas pelo trabalhador: 
“a ergoformação está no cruzamento do reconhecimento e da ancoragem, porque manter juntas as instruções e as oportunidades é ser competente" (Schwartz e Durrive, 2007, p. 304), Logo, fazer com que os sujeitos expressem em palavras os saberes construídos e constituídos durante a atividade é revelar as competências desenvolvidas durante a participação na CAP-PES.

Espera-se, nesse processo de educação continuada dos alunos (trabalhadores), oficializar um dispositivo de formação, integrando-o à grade curricular, enfatizando a construção compartilhada de conhecimentos e incentivando a efetivação e produção de tecnologias, como a leve e a leve-dura, para o campo da promoção e educação em saúde.

\section{Considerações finais}

O novo cenário da saúde, com seus novos conceitos, ações e propostas que formalizam a participação ativa de sujeitos sociais, criativos e transformadores da realidade, requer novas práticas educativas e de formação capazes de contribuir para provocar mudanças no campo da saúde.

Com base nos referencias teóricos da cartografia da micropolítica do trabalho vivo em ato, de Emerson Elias Merhy, da educação popular em saúde, de inspiração freireana, e da démarche ergológica, de Yves Schwartz, foram apresentadas sucintamente as bases teórico-metodológicas do dispositivo de formação intitulado "Comunidade ampliada de pesquisa em promoção da saúde", cujo objetivo é criar um ambiente educativo que possibilite ao trabalhador de saúde imergir na experiência de vida/saúde no campo da saúde promocional e propiciar o desenvolvimento de competências profissionais, produção de novos saberes, efetivação e produção de tecnologias e (trans)formação do trabalho na perspectiva de educação continuada.

Embora ainda em formulação/experimentação, acredita-se na capacidade da CAP-PES de contribuir para renovar as práticas de saúde coletiva e para transformar os sujeitos, preenchendo uma lacuna importante na formação para o trabalho em saúde, em especial, no campo da educação e saúde promocional. 


\section{Notas}

1 Analista de gestão em saúde do Instituto de Pesquisa Clínica Evandro Chagas, da Fundação Oswaldo Cruz (Ipec/Fiocruz), e docente da Escola Técnica Estadual de Saúde Herbert Daniel de Souza, da Fundação de Apoio à Escola Técnica (Faetec). Doutoranda do Programa de Pós-Graduação da Escola Nacional de Saúde Pública Sergio Arouca (Ensp) da Fiocruz. <suze.santanna@ipec.fiocruz.br>

Correspondência: Av. Brasil, n. 4.365, Manguinhos, CEP 21.040-900, Rio de Janeiro, RJ, Brasil.

2 Professora e pesquisadora do Programa de Pós-Graduação em Saúde Pública da Escola Nacional de Saúde Pública Sergio Arouca, da Fundação Oswaldo Cruz (Ensp/Fiocruz), e do Programa de Pós-Graduação em Pesquisa Clínica em Doenças Infecciosas do Instituto de Pesquisa Clínica Evandro Chagas (Ipec) da Fiocruz. Doutora em Saúde Coletiva pela Universidade Estadual de Campinas (Unicamp). <elida.hennington@ipec.fiocruz.br>

3 O conceito ampliado de saúde é fruto de reflexões teóricas, das práticas e movimentos sociais que resultaram na VIII Conferência Nacional de Saúde e foi consagrado no texto constitucional de 1988. Entendido "como resultado dos modos de organização social da produção, como efeito da composição de múltiplos fatores, exige que o Estado assuma a responsabilidade por uma política de saúde integrada às demais políticas sociais e econômicas e garanta a sua efetivação. Ratifica, também, o engajamento do setor saúde por condições de vida mais dignas e pelo exercício pleno da cidadania" (Campos, Barros e Castro, 2004, p. 746).

4 Para Schwartz, o conceito de atividade exibe três características: 1) transgressão: expressa as tensões entre o que é formalizado pelas normas e conceitos e o informal, o que não é bem codificado no nível da linguagem; 2) mediação: aspecto dinâmico dessa transgressão que, nas atividades de trabalho, se apresenta como algo obscuro porque se encontra incorporado nos corpos dos sujeitos; 3) contradição: instaura um debate de normas em que cada sujeito é convocado a gerir cotidianamente suas ações. A atividade é um impulso de vida, de saúde, sem limite predefinido, que sintetiza, cruza e liga tudo o que se representa separadamente - corpo/espírito, individual/coletivo, fazer/valores, privado/profissional, imposto/desejado etc. (Durrive e Schwartz, 2008).

5 A micropolítica é entendida como o agir cotidiano dos sujeitos, na relação entre si e no cenário em que eles se encontram (Franco, 2006).

$6 \mathrm{O}$ trabalho vivo refere-se ao trabalho em ato, trabalho dinâmico, criativo, não estruturado e de alta possibilidade inventiva (Franco, 2006).

7 Trabalho morto refere-se a todos os produtos-meio (ferramentas, matérias-primas) que são resultados de um trabalho humano anterior e que são utilizados pelo homem para realizar um dado trabalho (Malta e Merhy, 2003).

8 Oddone, psicólogo italiano, ficou conhecido como um dos propositores do Modelo Operário Italiano e, a partir da década de 1980, teve influência decisiva na atuação e consolidação da área de saúde do trabalhador no Brasil.

9 Vigilância de fatores de risco e proteção para doenças crônicas por inquérito telefônico (Vigitel) e Inquérito multicêntrico de saúde no estado de São Paulo/ISA-Camp - para o planejamento de ações na área de saúde - são exemplos clássicos desse tipo de inquérito. 


\section{Referências}

ALVES, Gehysa Guimarães; AERTS, Denise. As práticas educativas em saúde e a Estratégia Saúde da Família. Ciência \& Saúde Coletiva, Rio de Janeiro, v. 16, n. 1, p. 319-325, jan. 2011 .

BARROS, Maria Elizabeth Barros. Trabalhar: usar de si - sair de si. Interface - Comunicação, Saúde e Educação, Botucatu, v. 11, n. 22, p. 355-357, 2007.

BEZERRA, Luciana Caroline de Albuquerque; CAZARIN, Gisele; ALVES, Cinthia Kalyne de Almeida. Modelagem de programas: da teoria à operacionalização. In: SAMICO, Isabella et al. (Orgs.). Avaliação em saúde: bases conceituais e operacionais. Rio de Janeiro: MedBook, 2010. p. 65-78.

BRANDÃO, Carlos Rodrigues. (Org.). Pesquisa participante. São Paulo: Brasiliense, 2006.

BRASIL. Ministério da Saúde. Promoção da saúde: Declaração de Alma-Ata, Carta de Ottawa, Declaração de Adelaide, Declaração de Sundsvall, Declaração de Santafé de Bogotá, Declaração de Jacarta, Rede de Megapaíses e Declaração do México. 2. ed. Brasília: Ministério da Saúde, 2001.

BRITO, Jussara. Trabalho e saúde coletiva: o ponto de vista da atividade e das relações de gênero. Ciência \& Saúde Coletiva, Rio de Janeiro, v. 10, n. 4, p. 879-890, 2005.

CAMPOS, Gastão Wagner; BARROS, Regina Benevides; CASTRO, Adriana Miranda. Avaliação de política nacional de promoção da saúde. Ciência \& Saúde Coletiva, Rio de Janeiro, v. 9, n. 3, p. 745-749, 2004.

CANGUILHEM, Georges. O normal e o patológico. 2. ed. Trad. Maria Tereza R. de Carvalho Barrocas. Rio de Janeiro: Forense, 1982.

CARVALHO, Maria Alice Pessanha; ACIOLI, Sonia; STOTZ, Eduardo Navarro. Construção compartilhada do conhecimento. In: VASCONCELOS, Eymard Mourão (Org.). A saúde nas palavras e nos gestos: reflexões da Rede Educação Popular e Saúde. São Paulo: Hucitec, 2001. p. 101-114.

CUNHA, Gustavo Tenório. A construção da clínica ampliada na atenção básica. São Paulo: Hucitec, 2010.

DAVID, Maria Helena Scherlowski Leal; ACIOLI, Sonia. Mudanças na formação e no trabalho de enfermagem: uma perspectiva da educação popular e de saúde. Revista Brasileira de Enfermagem, Brasília, v. 63, n. 1, p. 127-31, fev. 2010

DURRIVE, Louis. Uma ação de formação no ambiente carcerário: um exemplo de abordagem das competências por meio da ergologia. In: DOLZ, Joaquim; OLLAGNIER, Edmé (Orgs.). O enigma da competência em educação. Porto Alegre: ArtMed, 2004. p. 173-187.

DURRIVE, Louis; SCHWARTZ, Yves. Glossário da ergologia. Laboreal, v. 4, n.1, p. 23-28, 2008. Disponível em: <http://laboreal.up. pt/revista/artigo.php?id=48u56oTV658223 4396587;63882 >. Acesso em: 21 maio 2011.

FERREIRA, Vitória Solange Coelho; FRANCO, Tulio Batista; MERHY, Emerson Elias. O processo de trabalho do agente comunitário de saúde e a reestruturação produtiva. Cadernos de Saúde Pública, Rio de Janeiro, v. 25, p. 898-907, 2009.

FEUERWERKER, Laura Camargo Macruz. Educação dos profissionais de saúde hoje: problemas, desafios, perspectivas e as propostas do Ministério da Saúde. Revista da Abeno, v. 3, n. 1, p. 24-27, jan./dez. 2003. Disponível em: <http://sites2.ufal.br/ unidadeacademica/famed/pos-graduacao/ mestrado-em-ensino-da-saude/educacao $\% 20$ dos \%20profissionais.pdf $>$. Acesso em: 15 maio 2011.

Modelos tecnoassistenciais, gestão e organização do trabalho em saúde: nada é 
indiferente no processo de luta para a consolidação do SUS. Interface - Comunicação, Saúde e Educação, Botucatu, v. 9, n. 18, p. 489-506, dez. 2005.

FIGARO, Roseli. Atividade de comunicação e de trabalho. Trabalho, Educação e Saúde, Rio de Janeiro, v. 6, n. 1, p. 107-145, 2008.

FRANCO, Tulio Batista. As redes na micropolítica do processo de trabalho em saúde. In: PINHEIRO, Roseni; MATTOS, Rubem Araújo (Orgs.). Gestão em redes. Rio de Janeiro: Cepesc-IMS/Uerj-Lappis, 2006. p. 459-474.

FREIRE, Paulo. Pedagogia do oprimido. 48 ed. Rio de Janeiro: Paz e Terra, 2005.

GOMES, Rafael et al. Integralidade como princípio ético e formativo: um ensaio sobre os valores éticos para estudos sobre o trabalho em equipe na saúde. In: PINHEIRO, Roseni; BARROS, Maria Elizabeth Barros; MATTOS, Rubem Araújo (Orgs.). Trabalho em equipe sob eixo da integralidade: valores, saberes e práticas. Rio de Janeiro: CepescIMS/Uerj, 2010.

HAFNER, Maria de Lourdes M. Botta et al. A formação médica e a clínica ampliada: resultados de uma experiência brasileira. Ciência \& Saúde Coletiva, Rio de Janeiro, v. 15, supl.1, p. 1.715-1.724, 2010.

HENNINGTON, Élida Azevedo. A. Gestão dos processos de trabalho e humanização em saúde: reflexões a partir da ergologia. Revista de Saúde Pública, São Paulo, v. 42, n. 3, p. 555-561, jun. 2008.

MALTA, Deborah Carvalho; MERHY, Emerson Elias. A micropolítica do processo de trabalho em saúde: revendo alguns conceitos. Reme - Revista Mineira de Enfermagem, Belo Horizonte, v. 7, n. 1, p. 61-66, jan./jul. 2003.

O percurso da linha do cuidado sob a perspectiva das doenças crônicas não transmissíveis. Interface - Comunicação, Saúde e Educação, Botucatu, v. 14, p. 243255, 2010.
MELLO, Maria Cristina de; FUGULIN, Fernanda Maria Togeiro; GAIDZINSKI, Raquel Rapone. O tempo no processo de trabalho em saúde: uma abordagem sociológica. Acta Paluista de Enfermagem, São Paulo, v. 20, n. 1, mar. 2007.

MELLO, Ana Lúcia Schaefer Ferreira de; MOYSES, Simone Tetu; MOYSES, Samuel Jorge. A universidade promotora de saúde e as mudanças na formação profissional. Interface - Comunicação, Saúde e Educação, Botucatu, v. 14, n. 34, p. 683-692, set. 2010.

MERHY, Emerson Elias. Saúde: a cartografia do trabalho vivo. São Paulo: Hucitec, 2007.

MERHY, Emerson Elias; FRANCO, Túlio Batista. Reestruturação produtiva em saúde. In: PEREIRA, Isabel B.; LIMA, Julio César F. (Orgs.). Dicionário da educação profissional em saúde. Rio de Janeiro: Escola Politécnica de Saúde Joaquim Venâncio, 2008a. p. 348-352. ; . Trabalho em saúde. In: PEREIRA, Isabel B.; LIMA, Julio César F. (Orgs.). Dicionário da educação profissional em saúde. Rio de Janeiro: Escola Politécnica de Saúde Joaquim Venâncio, 2008b. p. 427-432.

MERHY, Emerson Elias et al. (Orgs.). O trabalho em saúde: olhando e experienciando o SUS no cotidiano. 2. ed. São Paulo: Hucitec, 2004.

NEVES, Tatiana Pereira. As contribuições da ergologia para a compreensão da biossegurança como processo educativo: perspectivas para a saúde ambiental e do trabalhador. O Mundo da Saúde São Paulo, São Paulo, v. 32, n.3, p. 367-375, 2008.

PEDROSA, José Ivo. Educação popular no Ministério da Saúde: identificando espaços e referências. In: BRASIL (Org.). Caderno de educação popular e saúde. Brasília: Ministério da Saúde, 2007. p. 13-17. Série B. Textos Básicos de Saúde.

Educação popular em saúde e gestão participativa no Sistema Único de Saúde. Revista de Atenção Primária à Saúde, Rio de Janeiro, v. 11, n. 3, p. 303-313, jul./set. 2008. 
PIRES, Denise. Reestruturação produtiva e o trabalho em saúde no Brasil. São Paulo: Annablume, 1998.

RABELLO, Lucíola Santos. Promoção da saúde: a construção social de um conceito em perspectiva comparada. Rio de Janeiro: Editora Fiocruz, 2010.

RIBEIRO, Edilza Maria; PIRES, Denise; BLANK, Vera Lúcia G. A teorização sobre processo de trabalho em saúde como instrumental para análise do trabalho no Programa Saúde da Família. Cadernos de Saúde Pública, Rio de Janeiro, v. 20, n. 2, p. 438446, abr. 2004.

SANT'ANNA, Suze Rosa; HENNINGTON, Élida Azevedo. Promoção da saúde e redução das vulnerabilidades: estratégia de produção de saberes e (trans)formação do trabalho em saúde com base na Ergologia. Interface - Comunicação, Saúde e Educação, Botucatu, v. 14, n. 32, p. 207-215, mar. 2010.

SCHWARTZ, Yves. Os ingredientes da competência: um exercício necessário para uma questão insolúvel. Educação \& Sociedade, Campinas, v. 19, n. 65, p. 101-140, dez. 1998.

A comunidade científica ampliada e o regime de produção de saberes. Trabalho \& Educação, Belo Horizonte, n. 7, p. 38-46, jul./dez. 2000.

Disciplina epistêmica disciplina ergológica: paidéia e politéia. Pro-Posições, Campinas, v. 13, n. 1, p. 126-149, jan./abr. 2002.

Ergonomia, filosofia e exterritorialidade. In: DANIELLOU, François (Coord.). A ergonomia em busca de seus princípios: debates epistemológicos. São Paulo: Edgar Blücher, 2004.
Entrevista. Trabalho, Educação,

Saúde, Rio de Janeiro, v. 4, n. 2, p. 457-466, 2006.

SCHWARTZ, Yves; DURRIVE, Louis. Trabalho e ergologia: conversas sobre a atividade humana. Niterói: EdUFF, 2007.

SILVA, José Paulo Vicente da; LIMA, Juliano de Carvalho. Sistema Único de Saúde: reafirmando seus princípios e diretrizes para fazer avançar a Reforma Sanitária brasileira. In: ESCOLA POLITÉCNICA DE SAÚDE JOAQUIM VENÂNCIO (Org.). Textos de apoio em políticas de saúde. Rio de Janeiro: Editora Fiocruz, 2005. p. 43-73.

SILVA, Kênia Lara da et al. Educação em enfermagem e os desafios para a promoção de saúde. Revista Brasileira de Enfermagem, Brasília, v. 62, n. 1, p. 86-91, 2009.

Atenção domiciliar como mudança do modelo tecnoassistencial. Revista de Saúde Pública, São Paulo, v. 44, p. 165-175, 2010.

STOTZ, Eduardo Navarro; DAVID, Helena Maria Scherlowski Leal; WONG-UN, Julio Alberto. Educação popular e saúde: trajetória, expressões e desafios de um movimento social. Revista de Atenção Primária à Saúde, Rio de Janeiro, v. 8, n.1, p. 49-60, 2005.

TRINQUET, Pierre. Mâttriser les risques du travail. Paris: PUF, 1996.

VASCONCELOS, E. M. Educação popular: instrumento de gestão participativa dos serviços de saúde. In: BRASIL (Org.). Cadernos de educação popular em saúde. Brasília: Ministério da Saúde, 2007. p. 18-30.

Educação popular e a atenção à saúde da família. São Paulo: Hucitec, 2008.

Recebido em 03/06/2011

Aprovado em 10/06/2011 